\title{
Optimasi Pemupukan Urea dalam Peningkatan Produksi Padi Gogo Lokal Aceh Timur
}

\author{
Ainul Mardiyah \\ Fakultas Pertanian, Universitas Samudra, Meurandeh, Langsa Lama, \\ Kota Langsa, Aceh 24415, Indonesia \\ ainulmardiyah@unsam.ac.id
}

\begin{abstract}
Abstrak
Perubahan iklim berdampak pada peningkatan luas lahan khususnya lahan kering sehingga menjadi ancaman terhadap ketersediaan pangan dunia. Penggunaan padi gogo untuk lahan kering bisa menjadi solusi untuk ketersediaan pangan dunia dengan meningkatkan produksi melalui pemupukan $\mathrm{N}$ yang optimum. Penelitian dilakukan di lahan penelitian Fakultas Pertanian Universitas Samudra, Langsa dengan ketinggian tempat $\pm 10 \mathrm{~m}$ dpl selama 1 musim tanam mulai bulan Agustus sampai Desember 2020. Penelitian disusun dengan menggunakan rancangan acak kelompok (RAK) dua faktor tiga ulangan dengan faktor pertama adalah varietas lokal Aceh Timur yaitu Sileso, Arias Kuning dan varietas pembanding padi unggul Inpago Unsoed 1. Faktor kedua adalah dosis pemupukan urea yang terdiri atas 4 taraf yaitu $0 \mathrm{~kg} / \mathrm{ha}, 75 \mathrm{~kg} / \mathrm{ha}, 150 \mathrm{~kg} / \mathrm{ha}$ dan 225 $\mathrm{kg} / \mathrm{ha}$. Hasil Penelitian menunjukkan kultivar lokal lebih efisien dalam penggunaan pupuk urea sementara varietas unggul lebih membutuhkan urea dalam jumlah lebih besar. Dosis optimum untuk kultivar Sileso sebesar $145.3 \mathrm{~kg}$ urea setara dengan $66.84 \mathrm{~kg} \mathrm{~N}$, kultivar Arias Kuning Sebesar $135 \mathrm{~kg}$ urea setara dengan $62.1 \mathrm{~kg} \mathrm{~N}$ dan varietas Inpago Unsoed 1 sebesar $184.4 \mathrm{~kg}$ urea setara dengan $84.8 \mathrm{~kg}$ N.
\end{abstract}

Kata Kunci: kultivar, pangan, produktivitas, optimasi.

\section{Latar Belakang}

Perubahan iklim berdampak pada peningkatan luas lahan khususnya lahan-lahan kering. Peningkatan luas lahan kering berdampak terhadap penurunan luas lahan pertanian sehingga menjadi ancaman terhadap ketersediaan pangan dunia. Untuk mengatasi permasalahan tersebut, penggunaan tanaman pangan yang toleran kekeringan dapat menjadi solusi. Penggunaan padi gogo untuk lahan kering bisa menjadi solusi untuk ketersediaan pangan dunia, hanya saja ketersediaan bibit padi gogo unggul masih sangat jarang ditemukan dipasaran. Petani umumnya menggunakan padi gogo lokal dengan teknlogi budidaya yang tidak optimal sehingga produksi tergolong rendah. Syahril (2017) dalam penelitiannya melaporkan produksi padi gogo lokal Aceh Timur hanya mampu berproduksi 3.6 ton/ha.

Peningkatan produksi padi gogo lokal dapat dilakukan dengan menggunakan teknologi yang tepat. Salah satunya dengan penggunaan dosis pemupukan yang tepat. Khusus untuk padi gogo lokal Aceh Timur, sampai saat ini belum ada penelitian yang melaporkan dosis pemupukan yang terbaik untuk peningkatan

AGROSAMUDRA, Jurnal Penelitian Vol. 8 No. 1 Jan-Jun 2021 
produksi. Salah satu pemupukan yang memiliki peranan penting dalam menyediakan hara bagi tanaman adalah pemupukan hara Nitrogen. Unsur Nitrogen dibutuhkan tanaman dalam jumlah besar bagi pertumbuhan tanaman (Damanik dkk, 2010) sedangkan kelebihan N selain menghambat pertumbuhan tanaman juga akan menimbulkan pencemaran terhadap lingkungan (Duan et al. 2007). Untuk itu perlu diteliti dosis optimum pemupukan Nitrogen terhadap padi lokal Aceh Timur.

\section{Bahan dan Metode}

Penelitian dilakukan di lahan penelitian Fakultas Pertanian Universitas Samudra, Langsa dengan ketinggian tempat $\pm 10 \mathrm{~m}$ dpl selama 1 musim tanam mulai bulan Agustus sampai Desember 2020. Bahan yang digunakan dalam penelitian ini adalah benih padi gogo kultivar Sileso, Arias Kuning dan variatas unggul Inpago Unsoed. Penelitian disusun dengan menggunakan rancangan acak kelompok (RAK) dua faktor tiga ulangan dengan faktor pertama adalah varietas lokal Aceh Timur yaitu Sileso, Arias Kuning dan varietas pembanding padi unggul Inpago Unsoed 1. Faktor kedua adalah dosis pemupukan urea yang terdiri atas 4 taraf yaitu $0 \mathrm{~kg} / \mathrm{ha}, 75 \mathrm{~kg} / \mathrm{ha}, 150 \mathrm{~kg} / \mathrm{ha}$ dan $225 \mathrm{~kg} / \mathrm{ha}$. Plot berukuran $90 \mathrm{~cm}$ x $150 \mathrm{~cm}$ dengan jumlah tanaman 15 tanaman dan 5 tanaman dijadikan sebagai tanaman sampel.

Benih padi gogo disemai selama 14 hari sebelum ditanam. Penanaman dilakukan dengan membuat lubang tanam dengan jarak tanam yang digunakan adalah $30 \mathrm{~cm}$ x $30 \mathrm{~cm}$ dengan setiap lubang tanam ditanami 1 butir benih. Pemupukan TSP dan KCl dilakukan satu kali dengan dosis $100 \mathrm{~kg} / \mathrm{ha}$. Pemupukan urea dilakukan dua kali sesuai dengan dosis perlakuan. Setengah perlakuan diberikan pada 7 hari setelah tanam dan pemupukan kedua setengah dari dosis perlakuan diberikan pada umur 45 hari setelah tanam. Parameter penelitian meliputi jumlah anakan (batang), jumlah anakan produktif (batang), umur panen (hari setelah tanam), produksi per tanaman (gram), dan produksi per plot (kg). Data yang diperoleh dianalisis dengan analisis ragam dan jika perlakuan berbepanguh nyata dilanjutkan dengan uji kurva respon.

\section{Hasil dan Pembahasan}

Hasil penelitian aplikasi berbagai dosis pupuk urea menunjukkan pengaruh yang nyata terhadap hasil padi gogo lokal Aceh Timur. Rataan hasil penelitian tiga varietas dari setiap parameter yang diamati dapat dilihat pada Tabel 1. 
Tabel 1. Rataan hasil penelitian tiga varietas dari setiap parameter yang diamati

\begin{tabular}{|c|c|c|c|}
\hline \multirow{2}{*}{ PupukUrea } & \multicolumn{3}{|c|}{ Varietas } \\
\hline & V1 (Sileso) & V2 (Arias Kuning) & V3 (Inpago Unsoes 1) \\
\hline & \multicolumn{3}{|c|}{ Jumlah anakan (batang) } \\
\hline $\mathrm{P}_{0}(0 \mathrm{~kg} / \mathrm{ha})$ & 16.67 & 16.33 & 18.33 \\
\hline $\mathrm{P}_{1}(75 \mathrm{~kg} / \mathrm{ha})$ & 20.00 & 17.67 & 18.00 \\
\hline $\mathrm{P}_{2}(150 \mathrm{~kg} / \mathrm{ha})$ & 24.00 & 20.67 & 19.33 \\
\hline \multirow[t]{2}{*}{$\mathrm{P}_{3}(225 \mathrm{~kg} / \mathrm{ha})$} & 26.00 & 24.00 & 21.33 \\
\hline & \multicolumn{3}{|c|}{ Jumlah anakan produktif (batang) } \\
\hline $\mathrm{P}_{0}(0 \mathrm{~kg} / \mathrm{ha})$ & 14.00 & 14.00 & 16.00 \\
\hline $\mathrm{P}_{1}(75 \mathrm{~kg} / \mathrm{ha})$ & 17.67 & 15.00 & 17.00 \\
\hline $\mathrm{P}_{2}(150 \mathrm{~kg} / \mathrm{ha})$ & 22.00 & 18.67 & 18.00 \\
\hline $\mathrm{P}_{3}(225 \mathrm{~kg} / \mathrm{ha})$ & 21.00 & 17.67 & 16.00 \\
\hline & \multicolumn{3}{|c|}{ Umur Panen (hari) } \\
\hline $\mathrm{P}_{0}(0 \mathrm{~kg} / \mathrm{ha})$ & 130.33 & 134.33 & 122.33 \\
\hline $\mathrm{P}_{1}(75 \mathrm{~kg} / \mathrm{ha})$ & 135.00 & 138.67 & 123.00 \\
\hline $\mathrm{P}_{2}(150 \mathrm{~kg} / \mathrm{ha})$ & 137.33 & 148.33 & 122.00 \\
\hline $\mathrm{P}_{3}(225 \mathrm{~kg} / \mathrm{ha})$ & 138.00 & 149.00 & 127.67 \\
\hline & \multicolumn{3}{|c|}{ Produksi per tanaman (gram) } \\
\hline $\mathrm{P}_{0}(0 \mathrm{~kg} / \mathrm{ha})$ & 101.33 & 97.00 & 87.00 \\
\hline $\mathrm{P}_{1}(75 \mathrm{~kg} / \mathrm{ha})$ & 115.58 & 110.83 & 106.00 \\
\hline $\mathrm{P}_{2}(150 \mathrm{~kg} / \mathrm{ha})$ & 121.00 & 117.00 & 122.00 \\
\hline $\mathrm{P}_{3}(225 \mathrm{~kg} / \mathrm{ha})$ & 115.58 & 108.00 & 118.67 \\
\hline & \multicolumn{3}{|c|}{ Produksi per plot (kg) } \\
\hline $\mathrm{P}_{0}(0 \mathrm{~kg} / \mathrm{ha})$ & 1.08 & 0.90 & 0.88 \\
\hline $\mathrm{P}_{1}(75 \mathrm{~kg} / \mathrm{ha})$ & 1.30 & 1.54 & 1.31 \\
\hline $\mathrm{P}_{2}(150 \mathrm{~kg} / \mathrm{ha})$ & 1.80 & 1.75 & 1.66 \\
\hline $\mathrm{P}_{3}(225 \mathrm{~kg} / \mathrm{ha})$ & 1.30 & 1.27 & 1.12 \\
\hline
\end{tabular}

Pemberian pupuk urea yang linear terhadap jumlah anakan dan umur panen dan memberikan pengaruh yang kwadratik pada parameter jumlah anakan produktif, produksi pertanaman dan produksi per plot. Grafik kwadratik pada parameter jumlah anakan produktif, produksi pertanaman dan produksi per plot memungkinkan diperoleh dosis yang optimum pada pemupukan urea.

Tabel 1 menunjukkan bahwa parameter jumlah anakan tertinggi terdapat pada varietas Sileso dengan dosis pemupukan $225 \mathrm{~kg}$ urea sedangkan yang terendah terdapat pada perlakuan Arias Kuning dengan dosis pemupukan $0 \mathrm{~kg} / \mathrm{ha}$ (kontrol). Terdapat peningkatan jumlah anakan dengan semakin meningkatnya dosis pemupukan urea (Gambar 1). Berbeda dengan parameter jumlah anakan 
produktif, terjadi peningkatan jumlah anakan produktif akibat perlakuan pemupukan pupuk urea sampai pada dosis $150 \mathrm{~kg} / \mathrm{ha}$ dan mengalami penurunan pada dosis $225 \mathrm{~kg} / \mathrm{ha}$ (Tabel 1). Hasil analisis ragam menunjukkan kurva yang kwadratik pada parameter jumlah anakan produktif. Gambar 2 menunjukkan grafik dan model kurva Y dari setiap varietas pada perlakuan pemupukan urea. Berdasarkan persamaan yang diperoleh, untuk menghasilkan jumlah anakan produktif tertinggi kultivar Sileso memiliki dosis urea optimum sebesar 190,47 kg/ha, kultivar Arias Kuning sebesar 216 kg/ha dan varitas Inpago unsoed 1 sebesar $216 \mathrm{~kg} / \mathrm{ha}$. Hail ini sejalan dengan penelitian dari Anhar dkk (2016) yang mengemukakan bahwa peningkatan pertumbuhan dan hasil padi lokal aceh varietas merah dapat diperoleh pada dosis diatas $200 \mathrm{kh} / \mathrm{ha}$.

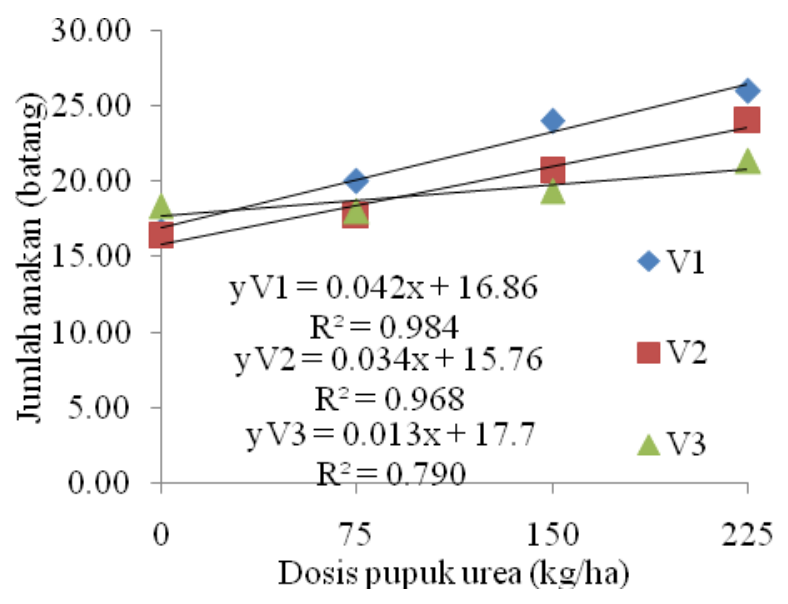

Gambar 1. Jumlah anakan akibat dosis pupuk urea 


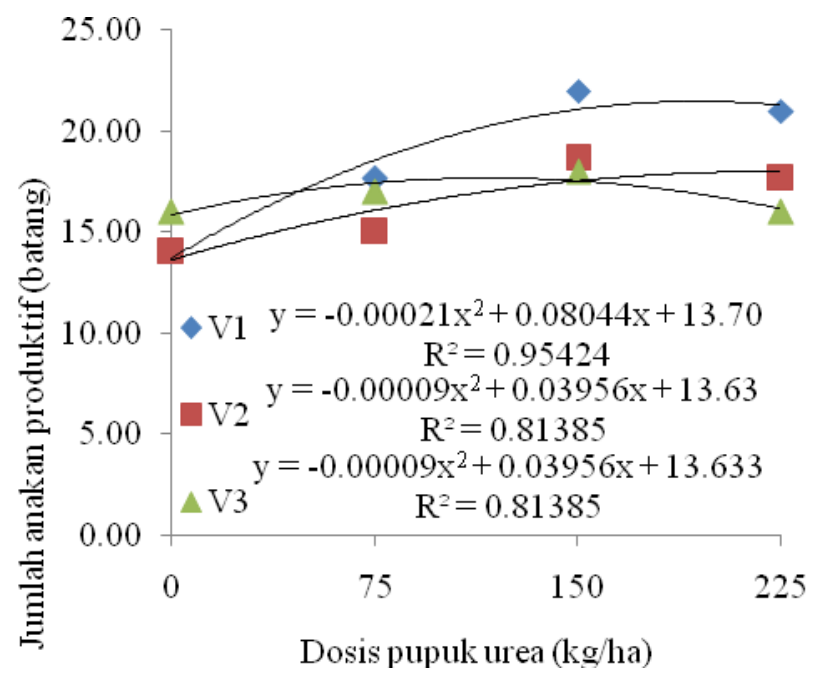

Gambar 2. Jumlah anakan produktif akibat dosis pupuk urea

Terjadi peningkatan produksi per tanaman sejalan dengan peningkatan dosis pupuk urea sampai pada dosis $150 \mathrm{~kg} / \mathrm{ha}$ dan mengalami penurunan pada dosis $225 \mathrm{~kg} / \mathrm{ha}$ (Tabel 1). Produksi per tanaman tertinggi terdapat pada perlakuan varietas Inpago Unsoed 1 yang diberikan pupuk urea sebesar $150 \mathrm{~kg} / \mathrm{ha}$ sedangkan yang terendah juga varietas Inpago Unsoed 1 yang tidak diberikan pupuk Urea. Hasil ini menunjukkan bahwa varieta unggul memiliki ketergantungan terhadap pemupukan N. Kultivar lokal Sileso dan Arias kuning memberikan hasil yang tidak begitu rendah pada perlakuan tanpa dipupuk Urea. Respon pemupukan urea pada parameter produksi per tanaman terdapat tiga varietas yang diuji dapat dilihat pada Gambar 3. Gambar 3 menunjukkan bahwa diperoleh grafik kwadratik pada 3 varietas yang diuji pada pemupukan urea. Berdasarkan persamaan yang diperoleh, untuk menghasilkan produksi pertanaman tertinggi kultivar Sileso memiliki dosis urea optimum sebesar $144.4 \mathrm{~kg} / \mathrm{ha}$ setara dengan $66.4 \mathrm{~kg} \mathrm{~N}$, kultivar arias Kuning sebesar $140 \mathrm{~kg} / \mathrm{ha}$ setara dengan $64.4 \mathrm{~kg} \mathrm{~N}$ dan varietas Inpago unsoed 1 sebesar $185.5 \mathrm{~kg} / \mathrm{ha}$ setara dengan $85.33 \mathrm{~kg}$ N. Hasil ini menunjukkan bahwa varietas unggul lebih membutuhkan urea yang lebih banyak untuk peningkatan produksi. Sejalan dengan penelitian Rohcmah dan Sugiyanta 2010 yang menyatakan bahwa penggunaan pupuk anorganik (200kg Urea/ha + 100kg SP36/ha + 100kg KCl/ha) mampu meningkatkan efektivitas agronomi tanaman padi. 


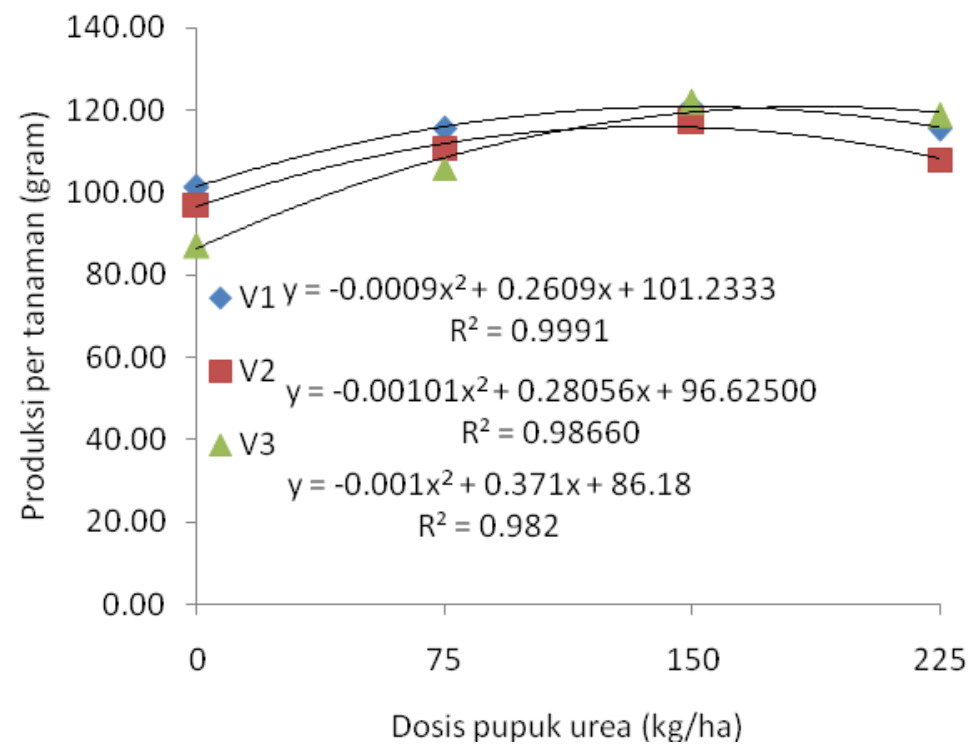

Gambar 3. Produksi per tanaman akibat dosis pupuk urea

Terjadi peningkatan produksi per plot dengan peningkatan dosis pupuk urea sampai pada dosis $150 \mathrm{~kg} / \mathrm{ha}$ dan mengalami penurunan pada dosis $225 \mathrm{~kg} / \mathrm{ha}$ (Tabel 1). Produksi per tanaman tertinggi terdapat pada perlakuan kultivar Sileso yang diberikan pupuk urea sebesar $150 \mathrm{~kg} / \mathrm{ha}$ sedangkan yang terendah juga varietas Inpago Unsoed 1 yang tidak diberikan pupuk Urea. Hasil ini menunjukkan bahwa varieta unggul memiliki ketergantungan terhadap pemupukan N. Kultivar lokal Sileso dan Arias kuning memberikan hasil yang tidak begitu rendah pada perlakuan tanpa dipupuk Urea. Respon pemupukan urea terdapat tiga varietas pada parameter produksi per plot yang diuji dapat dilihat pada Gambar 4. Gambar 4 menunjukkan bahwa diperoleh grafik kwadratik pada 3 varietas yang diuji pada pemupukan urea. Berdasarkan persamaan yang diperoleh, untuk menghasilkan produksi per plot tertinggi kultivar Sileso memiliki dosis urea optimum sebesar $146.17 \mathrm{~kg} / \mathrm{ha}$ setara dengan $67.24 \mathrm{~kg} \mathrm{~N}$, kultivar Arias Kuning sebesar $130 \mathrm{~kg} / \mathrm{ha}$ setara dengan $59.8 \mathrm{~kg} \mathrm{~N}$ dan varietas Inpago Unsoed 1 sebesar $183.3 \mathrm{~kg} / \mathrm{ha}$ setara dengan $84.33 \mathrm{~kg}$ N. Hasil ini menunjukkan bahwa varietas unggul lebih membutuhkan urea yang lebih banyak untuk peningkatan produksi. Berdasarkan hasil dari produksi per tanaman dan produksi per plot diperoleh dosis optimum untuk kultivar Sileso sebesar $145.3 \mathrm{~kg}$ urea setara dengan $66.84 \mathrm{~kg} \mathrm{~N}$, kultivar Arias Kuning sebesar $135 \mathrm{~kg}$ urea setara dengan $62.1 \mathrm{~kg} \mathrm{~N}$ dan varietas Inpago Unsoed 1 sebesar 184.4 $\mathrm{kg}$ urea setara dengan $84.8 \mathrm{~kg}$ N. Hasil ini menunjukkan bahwa kultivar lokal lebih efisien dalam penggunaan pupuk urea sementara varietas unggul lebih membutuhkan urea dalam jumlah lebih besar. Sejalan dengan penelitian dari Tota (2007) yang mengemukakan bahwa dosis pupuk berimbang untuk 
pemupukan varietas gogo unggul diberikan sebanyak $210 \mathrm{~kg}$ urea (berdasarkan pembacaan skala bagan warna daun/BWD), $100 \mathrm{~kg} \mathrm{SP} 36$, dan $100 \mathrm{~kg} \mathrm{KCl} /$ ha.

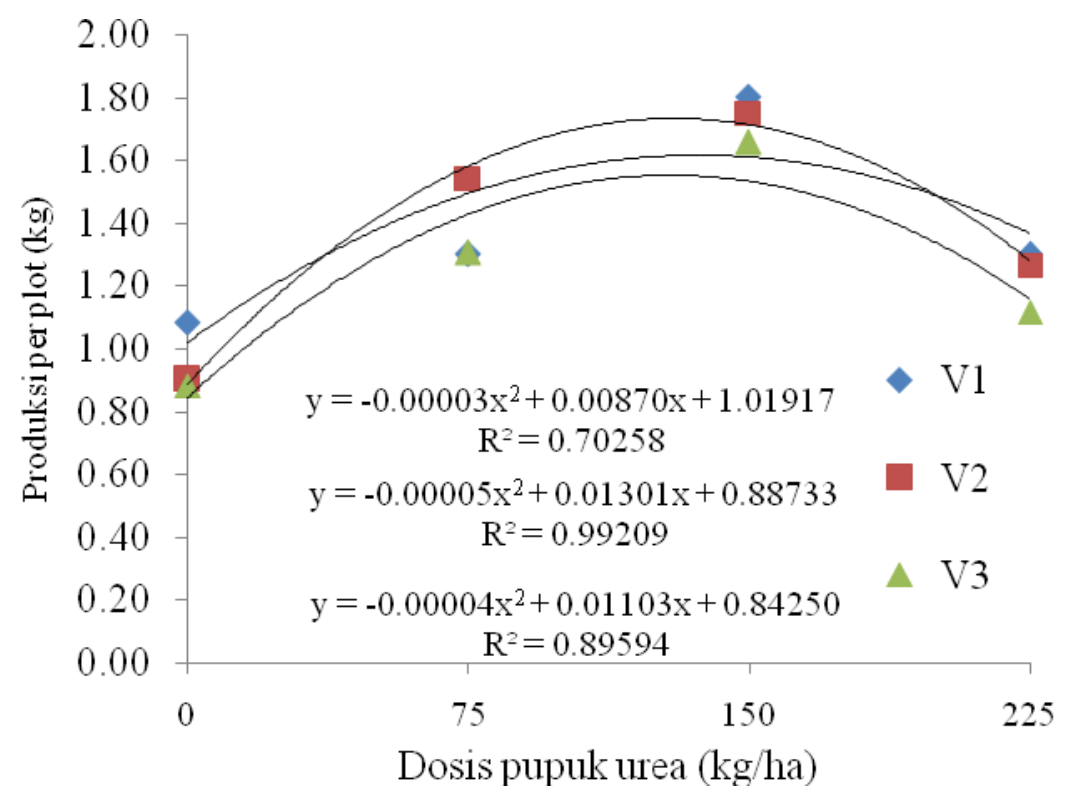

Gambar 4. Produksi per plot akibat dosis pupuk urea

\section{Kesimpulan}

Kultivar lokal lebih efisien dalam penggunaan pupuk urea sementara varietas unggul lebih membutuhkan urea dalam jumlah lebih besar. Dosis optimum untuk kultivar Sileso sebesar $145.3 \mathrm{~kg}$ urea setara dengan $66.84 \mathrm{~kg} \mathrm{~N}$, kultivar Arias Kuning sebesar $135 \mathrm{~kg}$ urea setara dengan $62.1 \mathrm{~kg} \mathrm{~N}$ dan varietas Inpago Unsoed 1 sebesar $184.4 \mathrm{~kg}$ urea setara dengan $84.8 \mathrm{~kg} \mathrm{~N}$. 


\section{Daftar Pustaka}

Anhar. R., E. Hayati., dan Efendi. 2016. Pengaruh Dosis Pupuk Urea Terhadap Pertumbuhan dan Produksi Plasma Nutfah Padi Lokal Asal Aceh. Jurnal Kawista No.1, Vol.1., P:30-36.

Damanik. M.M.B., Hasibuan, B. E., Fauzi., Sarifuddin., Hanum, H Kesuburan Tanah dan Pemupukan. USU Press. Medan.

Duan YH, YL Zhang, LY Ye, XR Fan, GH Xu, QR Shen. 2007. Responses of rice cultivars with different nitrogen use efficiency to partial nitrate nutrition. Ann Bot 99: 1153-1160.

Rohcmah, H. F. dan Sugiyanta. 2010. Pengaruh Pupuk Organik dan Anorganik Terhadap Pertumbuhan dan Hasil Padi Sawah (Oryza sativa L.). Makalah Seminar Departemen Agronomi dan Hortikultura IPB.

Syahril. M. 2017. Uji adaptasi beberapa kultivar padi gogo lokal kabupaten aceh timur di lahan kering kebun percobaan Universitas Samudra. J. Agrosamudra 4: 71-76.

Toha. H. M., 2007. Peningkatan produktivitas padi gogo melalui penerapan pengelolaan tanaman terpadu dengan introduksi varietas unggul. Jurnal Penelitian Pertanian Tanaman Pangan. Vol.26 No.3. $\mathrm{P}: 180-187$. 